\title{
Endotoxin contamination: a key element in the interpretation of nanosafety studies
}

The study of toxicity and potential risks of engineered nanoparticles is of particular importance in nanomedicine. Endotoxin, a common contaminant of bacterial origin, has biological effects that can mask the true biological effects of nanoparticles, if its presence is overlooked. In this review, we report the features of nanoparticle contamination by endotoxin, and the different biological effects of endotoxincontaminated nanoparticles. We will describe different methods for endotoxin detection applied to nanoparticles, and discuss their pros and cons. Eventually, we describe various methods for eliminating endotoxin contamination in nanoparticles. Although there is no universal technique for efficiently removing endotoxin from nanoparticles, specific solutions can be found case by case, which can allow us to perform nanosafety studies in biologically relevant conditions.

First draft submitted: 19 August 2015; Accepted for publication: 11 November 2015; Published online: 20 January 2016

\section{Keywords: endotoxin contamination $\bullet$ endotoxin elimination $\bullet$ LAL assay $\bullet$ nanomaterials} - nanosafety

The effects of engineered nanomaterials on the biological processes and, consequently, their safety for human health and the environmental are currently a topic of considerable interest. As for all novel nanomaterials, with particular regard to nanomedicines and health-related nanomaterials, immunological safety is a major aspect, given the key role of the immune system in defending the integrity of our body and maintaining its health. Several studies have shown that different kinds of nanomaterials can trigger inflammation in different in vitro and in vivo models, suggesting a possible risk for human health [1-3]. However, when considering these kind of studies, we should be aware of the fact that engineered nanomaterials might be contaminated by microbial components, such as bacterial endotoxin (also known as lipopolysaccharide [LPS]), a biologically active molecule with significant toxic and inflammatory effects. The innate immune system is exquisitely able to recognize and react to foreign agents, particularly microbial products. The presence of endotoxin can generate misleading experimental results both in in vitro and in vivo assays aiming at evaluating the toxic and inflammatory effects of nanomaterials. Therefore, it is important to discriminate between the biological effects from the unrecognized contaminants from the bona fide nanoeffects, when assessing the possible inflammatory/toxic effects of nanomaterials $[4,5]$.

\section{Bacterial endotoxin}

Endotoxin or LPS is a large molecule (molecular weight $200-1000 \mathrm{kDa}$ ) found on the outer membrane of Gram-negative bacteria. Endotoxin consists of a polysaccharide region and a lipid region (lipid A), which is responsible for inducing toxicity. In mammals, including humans, the toxic/inflammatory effects of LPS are mediated by the TLR4 sig-
Yang Li*,1 \& Diana Boraschi'

'Laboratory of Innate Immunity \& Cytokines, Institute of Protein Biochemistry, National Research Council, 80131 Naples, Italy

*Author for correspondence: yang.li.nano@gmail.com
Future fsg 
naling pathway. LPS binds to the LPS-binding protein, and then engages the TLR4 receptor with the support of the co-receptors CD14 and MD2, thereby initiating cell activation. TLR4 is expressed by many cell types, which are therefore responsive to LPS challenge. Among these, activation of innate immune cells such as monocytes and macrophages by LPS through TLR4 is a major step of the defensive inflammatory response against bacteria $[6-8]$. LPS-stimulated cells produce a variety of inflammatory factors, including the cytokines IL-1 $\beta$, TNF- $\alpha$ and IL-6. Our previous research has shown that as low as $0.1 \mathrm{EU} / \mathrm{ml}$ of LPS/endotoxin can upregulate the expression of inflammatory genes in primary human monocytes [9].

Endotoxin is very toxic to humans and could cause various life-threatening diseases. Endotoxin acquired from the environment can cause respiratory symptoms, pulmonary inflammation and asthma [10-16]. High levels of endotoxin in blood circulation (called endotoxemia) can occur in some systemic infections or severe trauma, causing a systemic response such as fever, hypotensive shock, impaired organ function and eventually multiple organ failure and death [17,18]. Therefore, intravenously (iv.) administered drugs and surgical instruments must be endotoxin-free, to avoid severe effects due to contaminating LPS. The maximum permissible endotoxin levels in iv. drugs have been declared and regulated by the US FDA as early as 1985 and updated thereafter [19]. This regulation obliges pharmaceutical companies to follow and control their iv. drugs for bacterial endotoxin/pyrogen contaminations.

\section{Endotoxin contamination is common in nanomaterials}

Endotoxin is a heat-stable ubiquitous contaminant. It is present in almost all chemicals and glassware used in laboratories, unless specific precautions are taken [20]. It is important to be aware that endotoxin cannot be eliminated by sterilization methods [21]. Our evaluation on a number of commercially available nanomaterials showed that most of them are contaminated by endotoxin [Unpublished Data]. A previous study has shown that different batches of the same nanomaterial synthesized in the same laboratory have different levels of endotoxin contamination depending on the variability in the cleanliness during the synthetic procedure (Figure 1) [9]. These findings underline the notion that endotoxin contamination commonly occurs in nanomaterial samples if no precautions are taken during their synthesis [22].

Given the highly reactive nature of their surface, nanomaterials can adsorb a wide range of molecules from the surrounding milieu, to reduce their surface- free energy. Hence, unintentional contaminants can be accumulated on the surface of nanomaterials by adsorption of air- or solution-borne species [23]. Endotoxin is one of the molecules that can attach to nanomaterials. Endotoxin is likely to adhere to hydrophobic surfaces through its lipid moiety, while its phosphate group allows it to bind to positively charged surfaces. Therefore, endotoxin is in theory able to attach to all kinds of surfaces $[20,23]$. Because of these features, endotoxin is not only a contaminant in nanomaterials, but an extensive contaminant in all kinds of biomaterials [20,24]. This situation suggests caution in the interpretation of data showing the toxic/inflammatory effects of nanomaterials, since the unrecognized presence of endotoxin in nanomaterials/biomaterials may actually account for most of the observed effects or synergize with nanomaterials to induce cell activation or toxicity. Thus, the reliability of nanotoxicological data, either in vitro or in vivo, depends on discriminating true nanoeffects from the effects of biologically active contaminants, of which bacterial endotoxin is the most common.

\section{Endotoxin effects in nanomaterials}

As mentioned above, endotoxin binds easily on the surface of nanoparticles. More than a decade ago Darkow et al. have tested endotoxin binding to functionalized nanoparticles. They showed that the capacity of binding endotoxin depends on the nanoparticles' ability to form Coulomb and van der Waals interactions with the endotoxin molecule, which is influenced by the nature of the suspension medium [25]. Karl et al. have also shown that endotoxin could adsorb to nanoparticles' surface, and that such adsorption was reduced when the nanoparticle surface was pretreated with phosphate. This pretreatment might cause particle aggregation thereby reducing the surface area available for LPS adsorption [26]. A recent study tested the LPS adsorption on the surface of functionalized paramagnetic nanoparticles, showing strong interaction between nanoparticles and the lipid A portion of LPS [27]. Another study on the interaction between LPS and polystyrene latex particles' surfaces proved that hydrophobic lipid A strongly binds to the surface of polystyrene particles. The orientation of the LPS molecules on the particles' surface was shown to be similar to that observed in the outer membrane of bacteria [28]. A more recent study showed that the polysaccharidic chain of LPS could strongly bind to the surface of $\mathrm{Al}_{2} \mathrm{O}_{3}$ nanoparticles, and LPS formed a layer on the nanoparticle surface detectable by atomic force microscopy [29]. The same study also showed that high $\mathrm{pH}$, ionic strength and sulfate concentration can decrease the adsorption of LPS molecules on nanoparticles [29]. 
(A)

\begin{tabular}{|c|c|c|}
\hline \multirow{2}{*}{ Au NPs 4 nm } & \multicolumn{2}{|c|}{ Endotoxin (EU/ml) in } \\
\cline { 2 - 3 } & Solvent & NPs \\
\hline \multirow{2}{*}{ Wet \#1 } & 5.9 & 151.6 \\
\hline \multirow{2}{*}{ Wet \#2 } & 1.1 & $<1.0$ \\
\hline \multirow{2}{*}{ Wet \#3 } & 27.8 & $<1.0$ \\
\hline Wet \#4 & $<1.0$ & 3.4 \\
\hline
\end{tabular}

Batch to batch variation

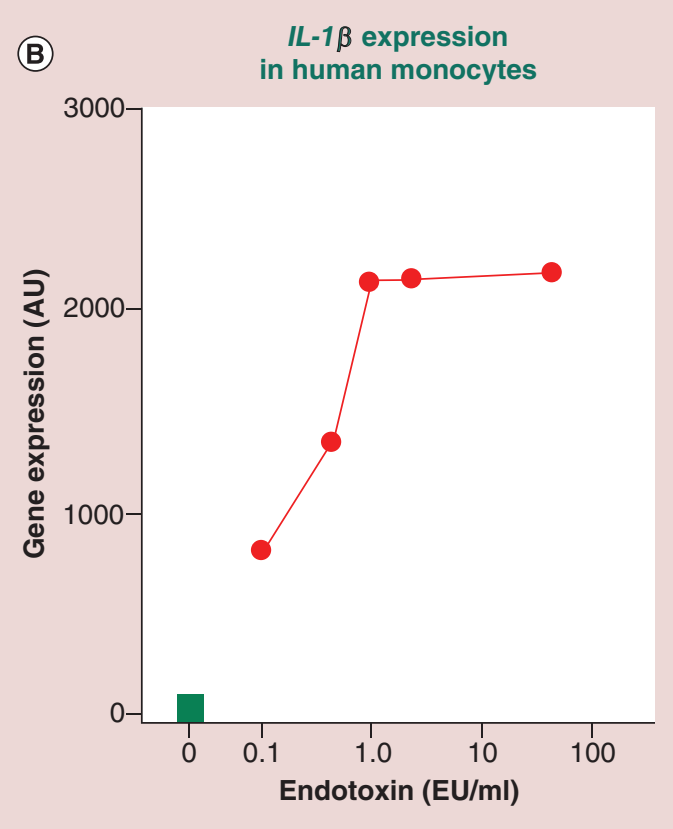

Figure 1. Endotoxin contamination in freshly synthesized gold nanoparticles. Left panel: endotoxin contamination in four different batches of $4 \mathrm{~nm}$ spherical Au NPs synthesized in the same laboratory. Right panel: the biological response to endotoxin by human primary blood monocytes shows that as little as $0.1 \mathrm{EU} / \mathrm{ml}$ of endotoxin can induce a potent reaction (upregulation of the inflammatory IL1B gene).

AU: Arbitrary units; Au NPs: Gold nanoparticles.

Reproduced with permission from [9] () BioMedCentral.

Eventually, our recent data show that endotoxin is rapidly and stably adsorbed to gold nanoparticles' surface in a dose-dependent manner [30]. Indeed, because of the high affinity of nanoparticles for endotoxin, several studies are aiming at using nanoparticles for removing endotoxin contamination (see below).

We thus know that endotoxin could bind to the nanomaterials surface, but what are the biological effects of this endotoxin contamination? We have already mentioned that LPS has potent inflammatory activity, which mainly goes through the activation of the TLR4 receptor on the surface of innate/inflammatory leukocytes. Activation of the NLRP3 inflammasome is a key element in inflammatory activation, as it leads to the production of the active form of the cytokine IL-1 $\beta$, which has a central role in both protective and pathological inflammation [31,32]. Endotoxin not only induces the upregulation of the gene encoding pro-IL-1 $\beta$, the inactive form of IL-1 $\beta$ [33], but it also primes the NLRP3 inflammasome to respond to activating stimuli such as lysosomal cathepsins or ATP [34-36]. Thus, the presence of endotoxin in nanoparticles may actually take part in all phases of IL-1-dependent inflammation, by inducing gene upregulation and also inflammasome activation. Several studies have shown that nanoparticles van actually bind and activate the LPS receptor TLR4 [37-40], and other studies have shown that nanoparticles can

activate the NLRP3 inflammasome by diverse mechanisms [41,42]. The involvement of possible contamination with endotoxin should be thoroughly examined in all studies, like those mentioned above, in which LPS is known to be a major activating stimulus, in order to dissect the bona fide effects of nanoparticles from those due to the presence of endotoxin.

Some researchers have already addressed the effect of endotoxin adsorbed on nanoparticles (Table 1). Cho et al. have investigated the interaction of orthopaedic wear particles with endotoxin, and found that the presence of endotoxin adsorbed on the particles can markedly enhance their inflammatory activity and affect implant loosening by inducing localized inflammation [43]. Ashwood et al. showed that $200 \mathrm{~nm}$ titanium dioxide nanoparticles can strongly bind LPS bridged by calcium cations, and that the LPSnanoparticle complexes can significantly increase the caspase-1-dependent IL-1 $\beta$ secretion and apoptoticlike cell death as compared with clean nanoparticles and to LPS alone. These effects can be inhibited by blocking both phagocytosis and receptor-mediated uptake of nanoparticles [44]. A few studies have indicated that micro-sized particles containing LPS can cause a significant increase of inflammatory cytokine production in primary human monocytes $[45,46]$ and murine RAW264.7 macrophage-like tumor cells [47]. Other data showed that co-administration of endo- 


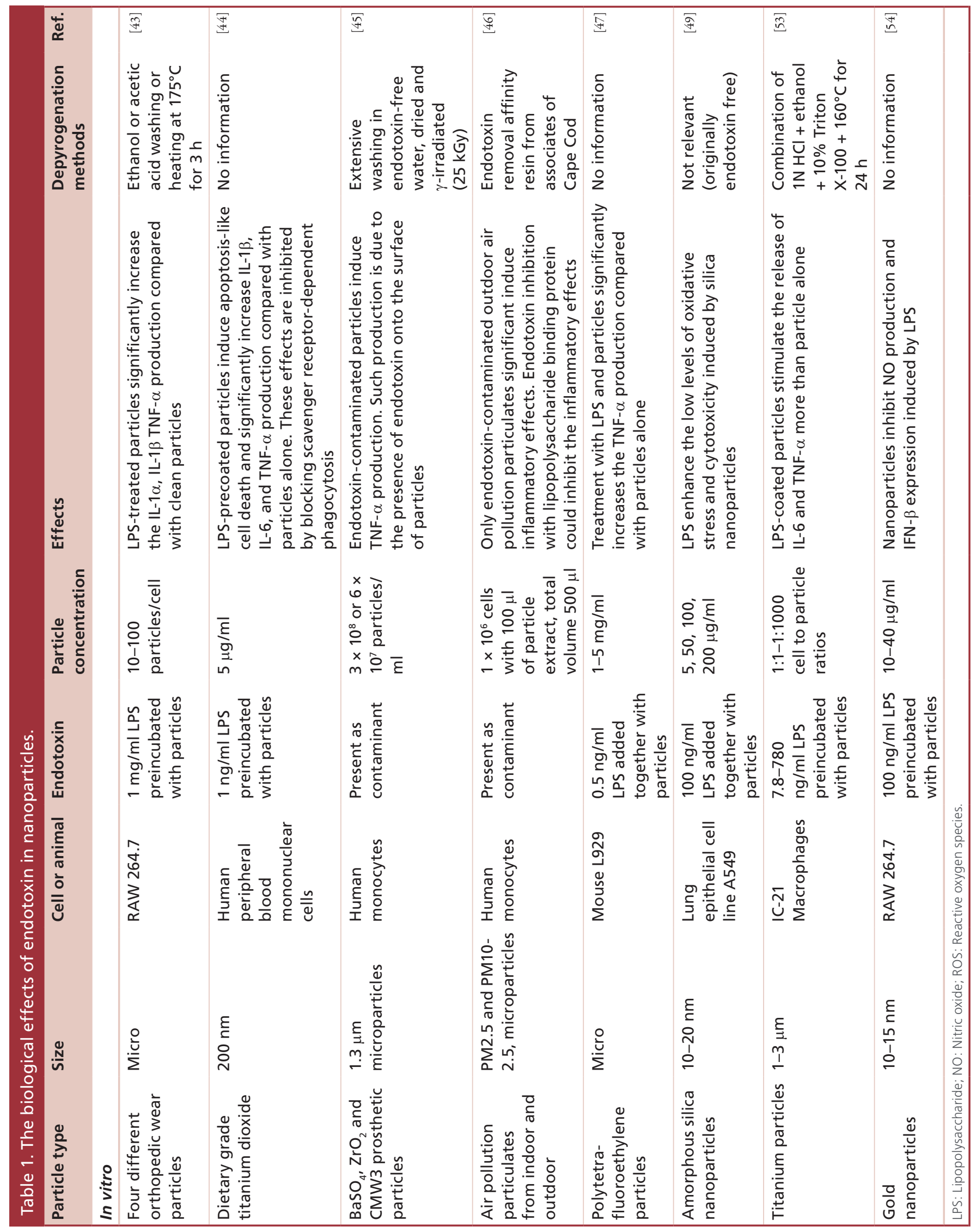




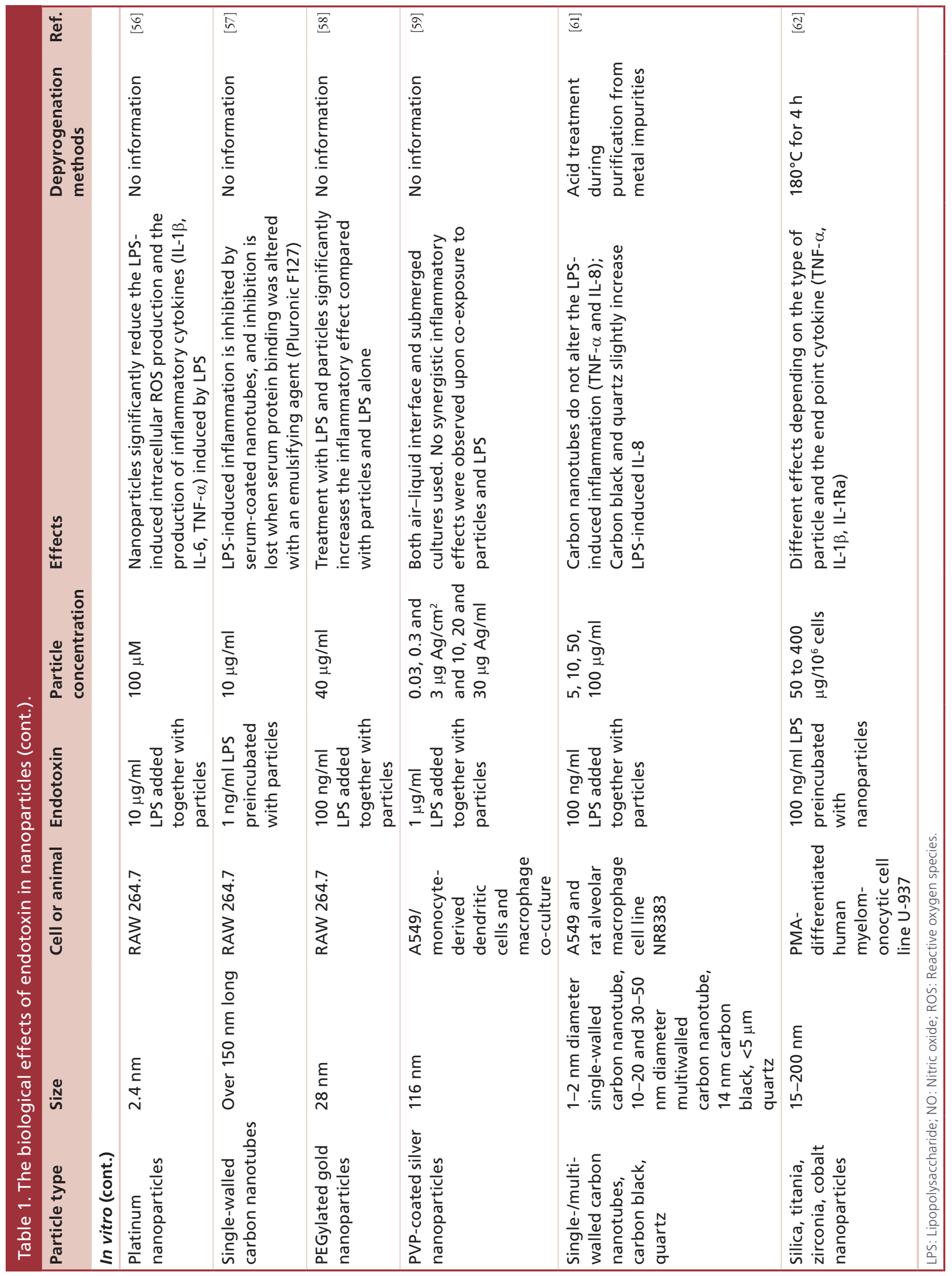




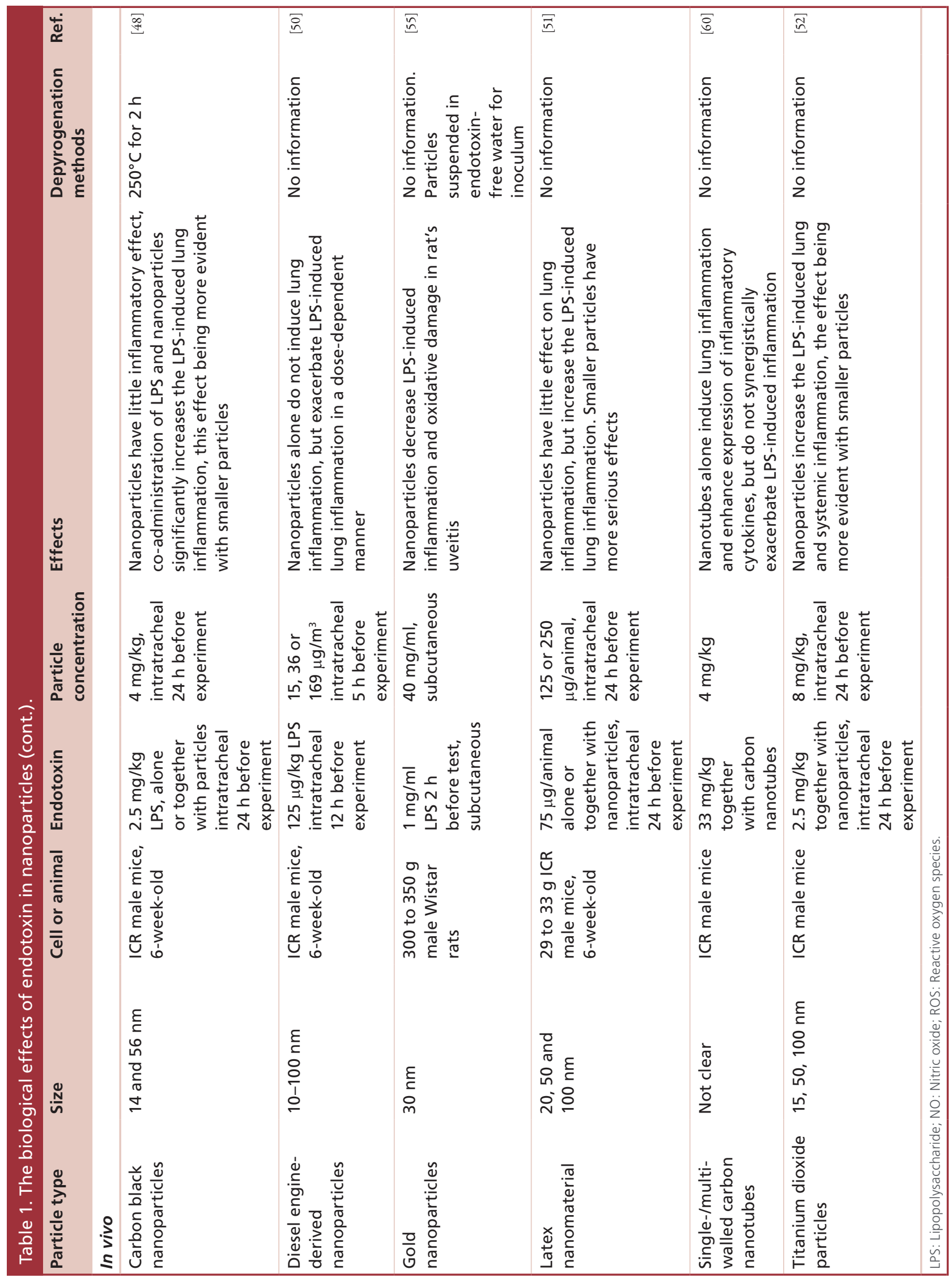


toxin could promote the adverse effects of engineered nanoparticles on lung functions both in vitro and in vivo [48-52]. Titanium particles, which deliberately contaminated with endotoxin, triggered inflammation in macrophages by inducing the production of inflammatory cytokines. However, these inflammatory effects of contaminated titanium particles seem to be quantitatively weaker than those obtained with endotoxin alone, implying that upon binding, endotoxin partly loses its activity [53]. However, the unclear study design does not allow a precise quantitative comparison of the concentrations of bound versus unbound endotoxin, and therefore the data reported cannot be considered conclusive. The possibility may also exist that the titanium particles had an anti-inflammatory effect that counteracted the endotoxin activity. In this direction, $\mathrm{Ma}$ et al. have proved that the gold nanoparticles can suppress the endotoxin-induced $\mathrm{NO}$ production by inhibiting the NF- $\kappa B$ and IFN- $\beta / S T A T 1$ pathways in RAW264.7 cells [54]. Furthermore, Pereira et al. showed that gold nanoparticles could inhibit cell activation induced by endotoxin through the TLR4-NFKB pathway, resulting in decreased inflammation and oxidative damage in rat's uveitis [55]. Platinum nanoparticles could inhibit the intracellular ROS production and inflammatory activities in murine macrophages exposed to endotoxin and nanoparticles [56]. Single walled carbon nanotubes coated with serum proteins (mainly albumin) could inhibit LPS-induced cyclooxygenase-2 activation in RAW264.7 cells, an effect that was lost when the albumin adsorption was blocked by treating the nanotube surface with a nonionic surfactant [57]. On the other hand, Liu and co-authors have proven that gold nanoparticles can enhance LPSinduced NO production and inflammatory effects in macrophage cell lines [58]. Our recent studies also show that endotoxin-treated gold nanoparticles are highly active in inducing the inflammatory response of human monocytes in vitro compared with the clean gold nanoparticles, which have no effect [30]. However, other studies show that LPS does not synergize with nanoparticles in inducing inflammatory effects when co-administered with silver nanoparticles in vitro and carbon nanotubes in vivo and in vitro [59-61]. Lucarelli and co-authors found that different types of ceramic and metallic nanoparticles had different abilities that modulate the inflammatory/anti-inflammatory responses of human macrophage-like cells in vitro, depending both on the type of nanoparticle and on the presence of LPS [62]. Thus, the interaction of endotoxin with nanoparticles may vary depending on the type, shape and surface charge of the nanoparticles, the type and amount of endotoxin, and the cell type or biological entity/environment under investigation. In any case, there is little doubt that the presence of endotoxin may affect the impact of engineered nanoparticles on a biological system.

\section{Endotoxin measurement methods}

The biological effects of endotoxin could mask or interfere with the true biological effects of nanomaterials. Hence, reliably discriminating the endotoxin activity from the nanomaterials' intrinsic inflammatory activity is important for nanosafety studies. The rabbit pyrogen test (RPT) and the Limulus amoebocyte lysate (LAL) assay are the most commonly used endotoxin detection methods that are approved by FDA and EMA, and accepted by almost every country. FDA approved the RPT assay in 1943. However, due to the high cost and long turnaround time of the assay (and the need of using animals), RPT is now only applied in combination with the LAL test for analyzing the parenteral drugs during the earlier development phase. As the most popular endotoxin detection method, the LAL assay could supply fast, sensitive and reasonably specific endotoxin assessment. The LAL assay also measures the activity of $\beta$-glucan, which however can be inhibited by a specific buffer, thus making the assay specific for endotoxin. FDA issued the final guideline on LAL testing in 1987 [63]. In 2000, the US and the European Pharmacopoeias have issued harmonized documents for LAL testing. In July 2011, FDA has withdrawn the 1987 guideline on LAL assay, considering it obsolete and not reflecting the Agency's opinion on the topic anymore. Drug manufacturers should now refer to the US Pharmacopeia General Chapter 85 Bacterial Endotoxins Test, which provides information on the performance and acceptance criteria for endotoxin testing [64]. Similar documents can also be found in European, Chinese and Japanese Pharmacopoeias. The FDA published a new guidance recommendation in 2012, in which two new methods are discussed as alternative LAL methods, the recombinant Horseshoe Crab factor $\mathrm{C}$ assay (specific for endotoxin, not recognizing $\beta$-glucan) and the macrophage activation-type pyrogen test (very sensitive but not specific for endotoxin) [65]. However, the FDA recommends validating the alternative methods for each product.

In the LAL assay, an enzyme in the blood cells (amoebocytes) of the horseshoe crab Limulus polyphemus causes protein clotting when activated by endotoxin (Figure 2). There are three different variants of the LAL assay: gel-clot, chromogenic and turbidimetric, in which the reaction is measured by different means.

The LAL assays are designed for soluble molecules and are active within a certain range of ionic strength. Thus, each assay should be accurately validated when 


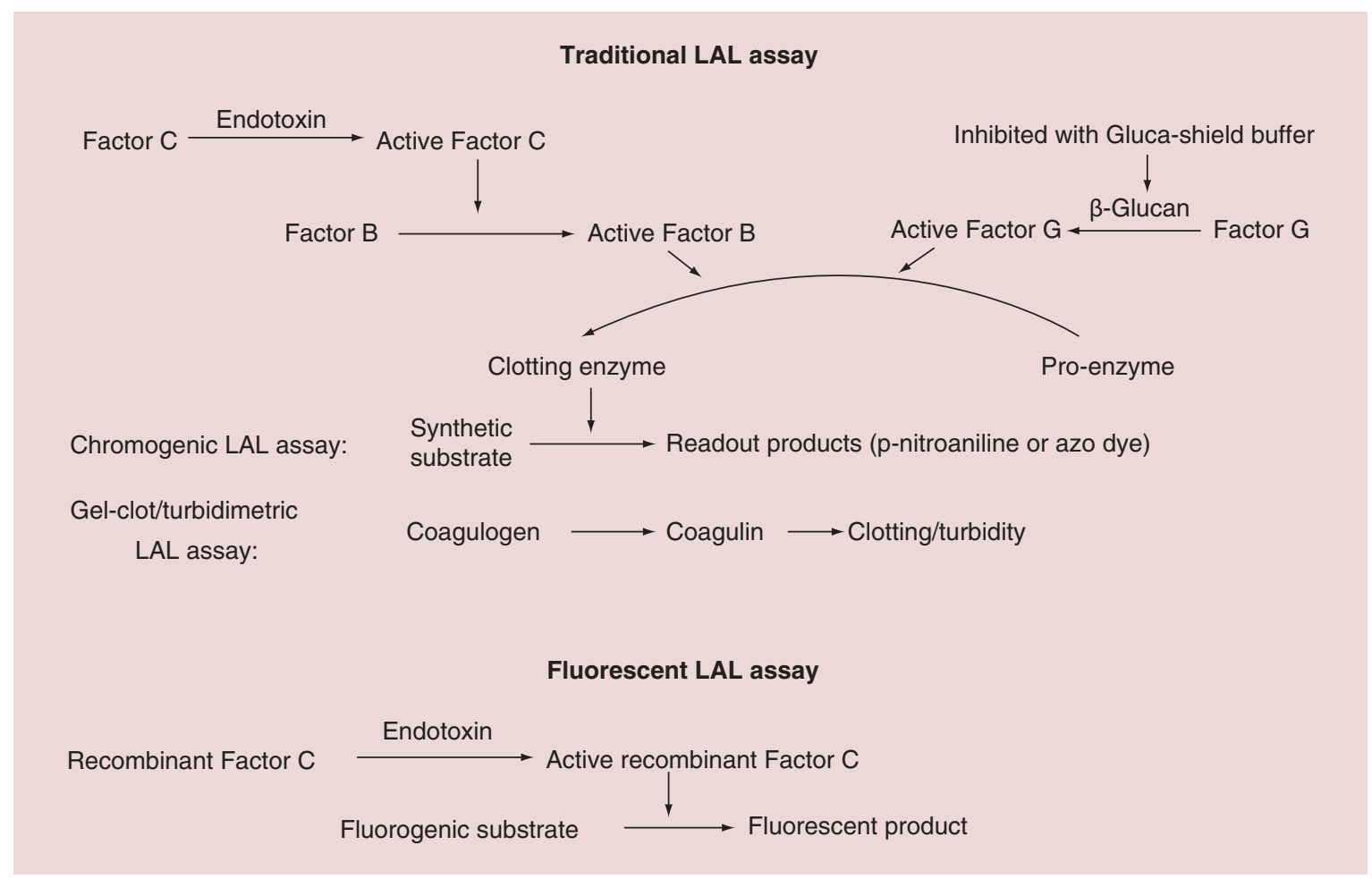

Figure 2. Schematic illustration of the Limulus amoebocyte lysate reaction. The reactions at the basis of the different types of LAL assays are indicated.

LAL: Limulus amoebocyte lysate.

applied to endotoxin detection in nanomaterials. In fact, the nanoobjects' peculiar physico-chemical properties (including their optical density) could significantly interfere with the LAL readouts, thereby leading to false results (Figure 3) [9,66]. The major advantages and disadvantages of the different LAL assays for testing endotoxin in nanomaterials are listed in Table 2.

The ISO 29701:2010 regulation mentions the possibility that nanomaterials can interfere with the optical readouts of LAL assays and recommends to run appropriate controls when measuring endotoxin in nanomaterial samples [67]. Despite this recommendation, little is known of the potential interference of nanomaterials with LAL assays. Thus, evaluating the interference of nanomaterials with the LAL assays' components and readouts is a necessary requirement in order to reliably detecting endotoxin contamination in nanomaterial preparations [4]. Several years ago, Brooks et al. tested the endotoxin contamination in microparticles by gelclot and chromogenic LAL assays. They found that the gel-clot assay is not suitable and suggested to use the chromogenic LAL method instead, given its high sensitivity and lack of interference by particles [45]. Dobrovolskaia et al. obtained contradictory results when using different LAL formats to test the same kind of nanoparticles [68]. They suggested that at least two LAL formats should be used to evaluate the pres- ence of endotoxin in nanomaterials. Moreover, when the results from two LAL assays differ by more than $25 \%$, the LAL results should be verified with RPT before the nanoproduct could enter the in vivo testing phase $[4,68]$. The Nanotechnology Characterization Laboratory of NCI (NIH, USA) has used this strategy to characterize nanoparticles for the presence of endotoxin and claimed to have solved the above-mentioned conflicting LAL results [68,69]. Smulders et al. compared different endotoxin detection assays (gel-clot LAL assay, chromogenic LAL assay and endotoxin detection method with TLR4 reporter cells) for an accurate evaluation of endotoxin contamination in nanomaterials [70]. They stated that the gel-clot LAL is not adequate, while the other methods were not significantly perturbed. However, they did not evaluate the interference of nanomaterials with the assays' readouts. Our experimental results with the chromogenic assays showed that interference by metal and metal oxide nanoparticles could occur not only at the level of the final readout (optical density of the nanoparticles at 405 or $540 \mathrm{~nm}$ ) but also by adsorption and subsequent quenching of the colored product released from the substrate ( $\mathrm{p}$-nitroaniline), thereby resulting in underestimating the endotoxin levels [66]. In a recent study, various types of silica nanoparticles were found able to interfere with the gel-clot LAL assay [71]. In another 


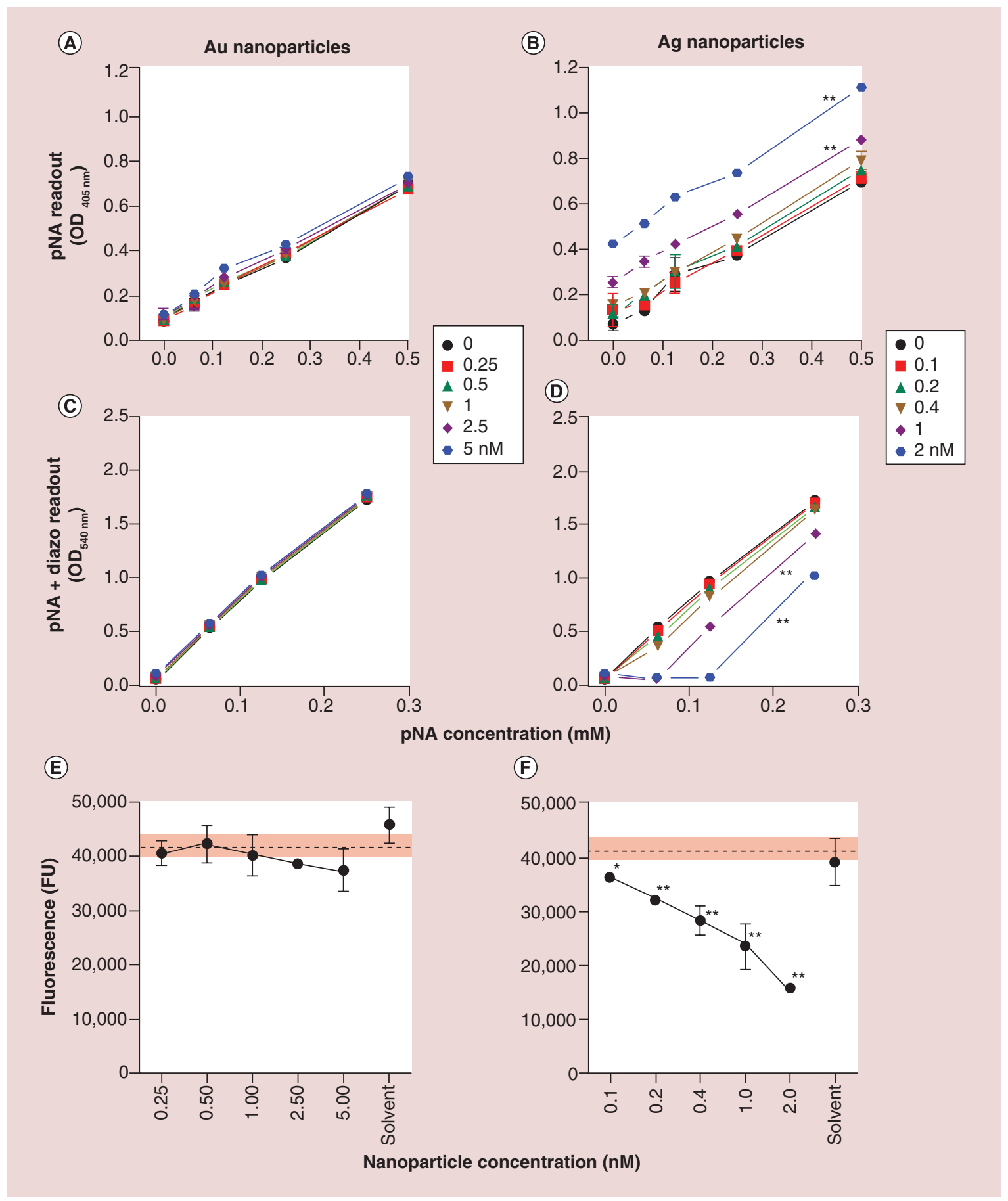

Figure 3. Interference of nanoparticles with the readouts of three different Limulus amoebocyte lysate assays. Interference by Au nanoparticles (A, C \& E) and by Ag nanoparticles (B, D \& F) was measured on the reading of pNA at $405 \mathrm{~nm}$ (A \& B), azo dye (pNA plus diazo reagents) at $540 \mathrm{~nm}$ (C \& D) and fluorescence at excitation/ emission 380/440 nm (E \& F). In (E \& F), the dotted lines are the positive fluorescence control (generated by $1 \mathrm{EU} / \mathrm{ml}$ endotoxin in the fluorogenic assay), and shaded areas represent the standard deviation above and below the mean. Data are the mean \pm standard deviation of triplicate determination within one test representative of three performed.

${ }^{*} p<0.05$ vs control; ${ }^{* *} p<0.01$ vs control.

FU: Fluorescence unit; OD: Optical density; pNA: Para-nitroaniline.

Reproduced with permission from [66]. 


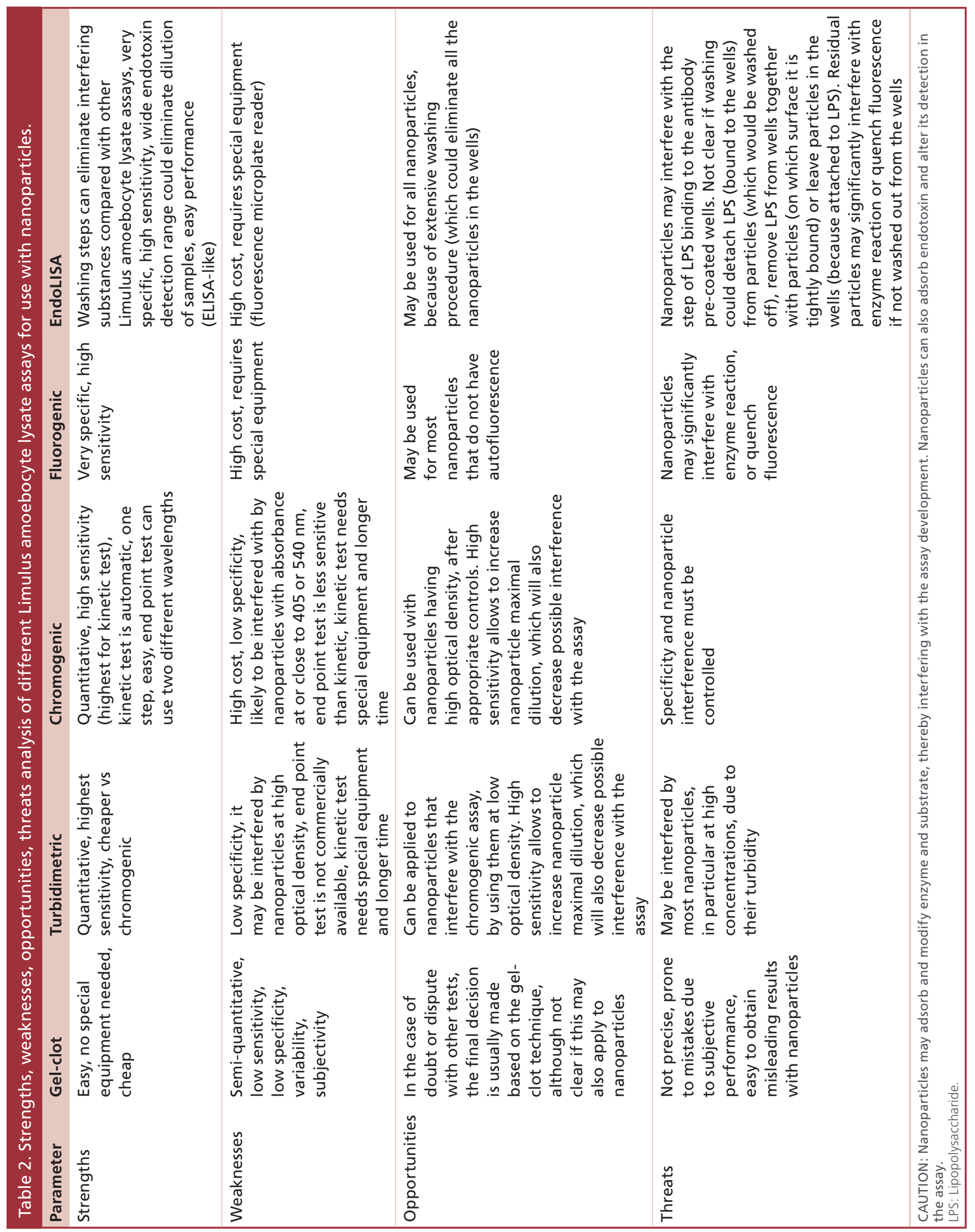


study, Dobrovolskaia et al. tested various clinical-grade nanoparticles with different LAL assays [69], and again found that the gel-clot LAL assay is not suitable. They eventually stated that no LAL format was optimal for all the tested nanoparticles. In industry, the gelclot LAL is commonly used to resolve discrepancy of results between different LAL formats. This approach was recently incorporated into a FDA recommendation as part of a guidance document [65]. However, as reported above, for the specific case of nanomaterials, the gel-clot LAL seems largely inappropriate. This evidence also challenges the guidance documents for bacterial endotoxin testing in nanomedicine products.

In order to eliminate the interference with the LAL assay, dilution of nanoparticle samples is recommended. A study published in 1984 reports that, among 333 drug products tested, 236 (71\%) interfered with the LAL test if not previously diluted or treated [72]. Thus, an accurate detection of endotoxin contamination can be achieved by diluting the nanoparticles to a concentration that shows no readout interference. Maximum valid dilution is the maximum dilution of the samples at which the presence of endotoxin is still detectable. The maximum valid dilution depends on the sensitivity of the LAL formats, the sample's initial concentration and the endotoxin limit under the clinical usage $(0.2 \mathrm{EU} / \mathrm{kg}$ for intrathecal drug; $5 \mathrm{EU} / \mathrm{kg}$ for drugs delivered by other routes) [64]. These limits however do not apply to nanosafety studies, in which clinical doses are not defined. Therefore, sample dilution should be carried out until interference disappears. In the case that endotoxin is below the assay's detection limit at such dilution, the endotoxin contamination of the sample could not be appropriately determined. For instance, a nanoparticle sample interferes with the assay unless diluted $1 / 1000$, and at this dilution the LPS detection is below the assay sensitivity limit $(0.1 \mathrm{EU} / \mathrm{ml})$. Thus, the endotoxin contamination of the sample cannot be determined, and we can only say that it is $<100 \mathrm{EU} / \mathrm{ml}$. In this case, either we select a different assay for determining the endotoxin content (less prone to interference by these particles), or we use the nanoparticles in nanosafety studies at concentrations that are for sure free of endotoxin (i.e., at least diluted 1/1000).

To eliminate the problem of nanoparticle interference with the LAL assay, an endotoxin extraction method is mentioned in the ISO 29701:2010 regulation. In fact, an extraction protocol could be found in the 'Guideline on LAL' as early as 1987 for medical devices [63]. Some extraction methods have been described for airborne dust samples and microparticles [45,73,74]. An extraction procedure has been developed for carbon nanomaterials in 2010 [75]. Smulders et al. performed an extraction procedure on nanoparticle samples in the attempt of measuring the endotoxin contamination by assessing the levels of extracted LPS, thereby avoiding the problem of nanoparticle interference with the assay. However, no measurable endotoxin could be recovered, suggesting that the extraction method was not efficient [70]. In fact, a study performed in 1999 has reported a significant loss of the endotoxin recovered after extraction from commercial titanium nanoparticles, leading to underestimation of the real endotoxin contamination [76]. Brooks et al. found that increasing the particle soaking time and including various sonication steps for extraction could increase the endotoxin recovery, but none of the extraction procedures could recover endotoxin at the level that is measurable in situ [45].

The European Centre for the Validation of Alternative Methods (ECVAM) published various highly sensitive and reliable bioassays for assessing pyrogens, such as the human PBMC activation assay and the human monocyte activation assay (MAT assay). Another possible assay is based on reporter cell lines obtained by co-transfecting the human TLR4, MD-2 and CD14 genes (all participating to the LPS receptor complex), and an inducible secreted embryonic alkaline phosphatase (SEAP) reporter gene into HEK293 cells. The SEAP is controlled by an IL-12 p 40 promoter that can be activated by NF-KB and activator protein 1 (AP-1). TLR4 agonists (e.g., LPS) can induce SEAP production by activating NF-KB and consequently activating the IL-12 p40 promoter. Thus, LPS contamination can be detected and quantitated in terms of SEAP production $[70,77]$. However, none of these bioassays is specific for endotoxin, because any pyrogen (theoretically including nanomaterials) can trigger the same biological effects (usually the NF-KB-dependent production of inflammatory cytokines) in the PBMC and MAT assays, since different molecules besides endotoxin can activate TLR4 or can activate NF-KB through other receptors. Thus, the pyrogen bioassays (also including the old RPT in vivo) are not adequate for specifically detecting the endotoxin contamination in nanomaterial samples. Dobrovolskaia et al. suggested to use the bioassays only for confirming LAL findings, limited to those nanomaterials that do not cause cytotoxicity [69]. Some reports showed that the TLR4 signaling pathway is involved in the uptake and inflammatory effects induced by titanium dioxide nanoparticles [78-80]. Some researchers have shown that functionalized gold nanoparticles and graphene oxide particles could induce TLR4-dependent activation, autophagy and macrophage death in the absence of endotoxin [37-39]. These results however, as in many other cases, could be considered valid only when the presence of endotoxin or of other TLR 4 ligands will 
be formally proven. Thus, the use of bioassays should be considered only for confirming LAL data, and in any case it should be subjected to the appropriate controls.

\section{Eliminating the endotoxin contamination in nanomaterials}

Nanomaterials that undergo health safety studies need to be sterilised, so as to avoid the presence and activity of contaminating bacteria. There are several sterilization methods that can be applied to nanomaterials, such as filtration [81,82], autoclaving [83], irradiation [84], the gas plasma method [85], and others (reviewed in [86]). These methods are effective in the removal or destruction of microbial contamination. However, all these sterilization techniques may, in most cases, alter the nanomaterials' physico-chemical properties, stability and toxicity/biological effects [85]. Therefore, for each nanomaterial a specific sterilization method should be applied that is validated as uninfluential on the physico-chemical and biological activities of the nanomaterials [85]. In any case, we should be aware that the sterilization processes are usually unable to removing endotoxin in nanomaterials' preparations. To date, still no efficient technique has been developed to remove endotoxin contamination in nanomaterials' samples. The difficulties in removing endotoxin from samples are due to the endotoxin's high variability in molecular weight, and to its $\mathrm{pH}$ and thermic stability. Endotoxin removal is a difficult issue not only for nanomaterials, but also for proteins for clinical use [87,88]. The endotoxin removal ability and the sample recovery rate of different endotoxin removal methods have been studied [89]. However, it should be noted that there is no gold standard for endotoxin removal, regardless of protein or nanoparticles. Therefore, the revalidation and recharacterization processes are always needed after endotoxin removal.

Several methods are used to remove endotoxin from samples, a process called 'depyrogenation' [90]. How much the depyrogenation methods can be applied to nanoparticles depends on the characteristics of the nanoparticles and, in many instances, they cannot be applied at all. A list of the most used methods and of their pros and cons is reported hereafter.

\section{Ultrafiltration}

Filtration through a $0.22 \mu \mathrm{m}$ sterilizing membrane is very useful for eliminating bacteria from soluble samples. Endotoxin, which is an heterogeneous molecule found in different conformations and aggregation states over a wide range of molecular weights (from 1 to $1000 \mathrm{kD}$ ), usually cannot be removed by filtration on the $0.22 \mu \mathrm{m}$ filter, although some aggregated forms could be removed by ultrafiltration. Some reports have shown that endotoxin is quite effectively retained by a $0.025 \mu \mathrm{m}$ filter, as endotoxin can adsorb to the filter membrane; the method has been used for removing endotoxin from water [91-93]. However, filtration of nanoparticle suspension may pose problems because the filter may also trap the particles and, if endotoxin is already adsorbed on the particle surface, the contaminated particles could go through the filter without losing the endotoxin.

\section{Gel filtration chromatography}

Size-exclusion chromatography (SEC) is a method that could be applied to eliminate endotoxin based on its size and molecular weight. SEC has been used for separating endotoxin from proteins and plasmid DNA [94,95]. However, as mentioned above, the wide range of the endotoxin size and molecular weight makes it difficult to remove all the endotoxin with this method $(0.8 \mathrm{EU} /$ $\mathrm{mg}$ still present in the purified sample; see [95]). In addition, there is no evidence showing the suitability of SEC for removing endotoxin from nanoparticles.

\section{Two-phase extraction}

By using detergents, endotoxin could be separated from sample solutions by a two-phase extraction method [96]. After mixing the detergent (e.g., Triton X-114) with sample solutions, endotoxin can be separated with centrifugation and a temperature increasing process from the water phase because of the nonpolar interaction of lipid A with the detergent. Normally, this process should be repeated until the endotoxin contamination falls below the threshold limit [87,96]. The two-phase extraction method is normally used to remove endotoxin from proteins, but it is also applied to nanoparticles. It has reported that gold nanoparticles became nonpyrogenic (tested by a RPT) after this two-phase depyrogenation [68]. The drawback is that a certain amount of detergent always remains in the sample solution, which asks for further procedures to remove it (adsorption or gel-filtration). All this implies a timeconsuming procedure and a significant product loss [96].

\section{Ion-exchange chromatography}

Endotoxin is normally negatively charged, and can therefore easily bind to an anion exchanger. On this basis, anion-exchange chromatography may be effective in removing endotoxin, and in fact this method is normally used to purify proteins from endotoxin contamination [87]. Again, whether this method is also applicable for the depyrogenation of nanoparticles has not been assessed. Moreover, only positive-charged nanoparticles could be subjected to anion-exchange chromatography, thereby significantly limiting its possible applicability to nanoparticle decontamination. 


\section{Affinity adsorption chromatography}

The affinity adsorption method is based on the use of an endotoxin-selective affinity sorbent that specifically binds and retains endotoxin. The antibiotic polymyxin $\mathrm{B}$ has high binding affinity to the lipid A part of endotoxin. Therefore, polymyxin B affinity columns are very effective in removing endotoxin contamination. However, since endotoxin is usually adsorbed to the surface of nanomaterials and is hardly released, the polymyxin B affinity columns are likely to remove the nanoparticles together with the endotoxin adsorbed on their surface, leading to a significant loss of nanoparticles [22]. Thus, the strategy of using affinity columns to remove endotoxin contamination from nanoparticles' solutions should be discarded if a loss of nanomaterials in the process cannot be accepted. Moreover, polymyxin B can stimulate human monocytes to produce IL-1 $\beta$ [97], which may cause problems of uncontrolled activation/toxicity if/when the polymyxin B is released from the column. There are many other commercial high affinity chromatographic endotoxin removal systems (e.g., ActiClean Etox, ReductEtox, Detoxi-Gel, EndoTrap) based on different endotoxin-adsorbing substances. Also in this case, there is no information on the ability of these methods in removing endotoxin from the surface of contaminated nanoparticles.

\section{Plasma discharge}

The plasma discharge method is an excellent method for removing bacteria, immunostimulatory components and pyrogens from the surface of materials such as surgical equipment, dental instruments and long-term prostetic implants. The plasma discharge method is effective for both sterilization and depyrogenation. The UV radiation from the plasma discharge process is allegedly responsible of the inactivation of spores. The etching/ erosion by the radicals and active species (e.g., atomic oxygen, $\mathrm{OH}$ radicals) produced by the plasma discharge is considered the most potent and direct mechanism for killing spores and microorganisms by destruction of their membrane, and it also destroys other contaminants such as pyrogens/endotoxin [98,99]. Many studies have shown that the plasma discharge method can be used for depyrogenation [99-103], as it achieves a $3 \log$ reduction of the initial pyrogen amount. PEG-coated gold nanoparticles treated by plasma discharge at $45^{\circ} \mathrm{C}$ for $50 \mathrm{~min}$ showed a strong alteration of the particles' characteristics (in particular alterations in the PEG coating) [85]. On the other hand, the plasma discharge treatment seems effective for tiopronin-coated gold nanoparticles, since the treatment has no effect on the physico-chemical properties and does not affect the particles' lack of toxicity, measured as induction of cell death and induction of ROS in the human U937 cell line [85]. Therefore, the plasma discharge method can be successfully used for depyrogenating nanoparticles, but the method should be tested and validated for each type of sample.

\section{Inactivation}

Since endotoxin removal from the particle surface is clearly problematic, the choice of endotoxin-destroying/ inactivating methods is apparently the most effective way of eliminating the problem of endotoxin bioactivity and toxicity. The common methods for pyrogen inactivation are acid-base hydrolysis, oxidation, treatment with sodium hydroxide and heating. However, all these are aggressive methods that normally cannot be applied to nanomaterials without changing their physico-chemical characteristics. Some reports have demonstrated that the endotoxin contamination of micro-sized particles could be removed by acid or sodium hydroxide treatment $[43,76]$. The endotoxin contamination in the microsized titanium particles on orthopedic implant decreased 100-times after treatment in alkali-ethanol and nitric acid [76]. Cho et al. also showed that micro-sized particles washed in acetic acid-ethanol were unable to stimulate the murine RAW264.7 cells to produce inflammatory cytokines [43]. In fact, the most efficient way of destroying endotoxin is incineration, which can be obtained, for instance, by dry heating at high temperatures $\left(180^{\circ} \mathrm{C}\right.$ for $3 \mathrm{~h}$ or $250^{\circ} \mathrm{C}$ for $30 \mathrm{~min}$ ) and that can reduce endotoxin activity by $5 \operatorname{logs}$ [90]. In general, the same effects can be obtained at higher temperatures for shorter times and at lower temperatures for longer times [90].

Matthews et al. showed that the micro-sized wear debris particles are endotoxin-free after treatment at $180^{\circ} \mathrm{C}$ for $3 \mathrm{~h}$ [104]. Another study showed that cobalt chrome particles (nano- and micro-sized) can be exposed to dry heating for depyrogenation $\left(180^{\circ} \mathrm{C}\right.$ for $\left.4 \mathrm{~h}\right)$. Intentionally contaminated particles were endotoxin-free after such treatment (from 90 to $<0.004 \mathrm{EU}$ ) [105]. Likewise, Cho et al. also have shown that micro-sized particles in powder can be depyrogenated by incineration $\left(175^{\circ} \mathrm{C}\right.$ for $\left.3 \mathrm{~h}\right)$, and the treated particles cannot induce inflammatory cytokine production (both at the gene and protein level) in RAW264.7 cells. The dry heating depyrogenation method turned out to be much more effective than the acetic acid-ethanol washing [43]. Similar results were also obtained by Schwab et al. They found that dry heating $\left(160^{\circ} \mathrm{C}\right.$ for $24 \mathrm{~h}$ ) was the most effective method to eliminate the endotoxin contamination in titanium micro-particles, compared with hydrochloric acid washing, ethanol washing and $10 \%$ Triton X-100 washing [53]. They found that repeated ethanol washings and dry heating was the most effective way to eliminate endotoxin in titanium particles, with a residual endotoxin contamination of $0.22 \mathrm{EU} / 2.5 \times 10^{6}$ particles. Unfortunately, 
the authors did not assess the initial contamination of their particles, and therefore we cannot know the real efficacy of their methods [53]. Other nanoparticles in powder (silicon oxide, titanium oxide, zirconium oxide and cobalt nanoparticles) can be depyrogenated at $180^{\circ} \mathrm{C}$ for $4 \mathrm{~h} \mathrm{[62].} \mathrm{Carbon} \mathrm{black} \mathrm{nanoparticles} \mathrm{can} \mathrm{be}$ submitted to depyrogenation at $250^{\circ} \mathrm{C}$ for $2 \mathrm{~h}$ without damage [48]. Other reports showed that treatment at $110^{\circ} \mathrm{C}$ for $12 \mathrm{~h}$ can depyrogenate hydroxyapatite particles used to coat prosthetic implants [106-108]. However, it should be noted that these hydroxyapatite particles were synthesized with sintering at $600^{\circ} \mathrm{C}$ or $1180^{\circ} \mathrm{C}$, temperatures at which LPS would be destroyed anyway.

From the available evidence, the incineration method can be applied to nanoparticles in solid form (powder), such as carbon nanotubes or titanium dioxide nanoparticles, which are resistant to the high temperature treatment. In any case, nanoparticles need to be recharacterized after the depyrogenation process, in order to make sure they have maintained their original physico-chemical characteristics.

\section{Other removal methods}

The oldest and simplest method for depyrogenation consists in rinsing the contaminated material with endotoxin-free water or washing in ethanol [90]. These methods can be used to remove endotoxin from particles used in implants and for surgical materials. It has been found that implant particles lose the ability to induce NO production in murine RAW264.7 cells after washing with $70 \%$ ethanol [109]. However, other studies reported that the $70 \%$ ethanol washing was unable to depyrogenate the micro-particles, which still induced the production of inflammatory cytokines in RAW264.7 cells [43]. The overall low removal efficiency of these washing and rinsing methods limits their application to nanoparticles, to which surface endotoxin is generally strongly adsorbed. In addition, these methods cannot be applied to particles coming from wet synthesis, because the rinsing/washing process will dilute or remove the nanoparticle stabilizing agents, and aggregation is likely to occur.

\section{Use of nanoparticles for depyrogenation}

Since endotoxin binds efficiently to the nanoparticle surface, nanoparticles can be used to remove endotoxin from samples $[26,110,111]$. While this approach is likely to work with samples in solution, it is not obvious that it could work for depyrogenating other nanoparticles. The endotoxin-capturing nanoparticles should have a very strong affinity for endotoxin for being able to displace it from the surface of other particles, a situation that might be difficult to achieve and control. Subsequently, the endotoxin-capturing nanoparticles should be removed from the sample (e.g., with a magnet if these are iron-based particles).

\section{Preventing contamination}

Because of the difficulty of endotoxin removal, preventing contamination during the nanoparticles synthesis would be the best way for obtaining endotoxin-free particles. This can be obtained by using only endotoxin-free reagents, instruments and glassware during the synthesis process [22]. It should be noted, however, that endotoxin-free conditions are not easy to achieve in chemical labs and therefore not everybody may be equipped for obtaining endotoxin-free particles. Moreover, the endotoxin-free condition of particles can be lost very easily because of the poor handling process, such as using endotoxin-presence containers, water and buffers [20].

\section{Conclusion \& future perspective}

Several biologically active microbial compounds present in the environment can contaminate nanomaterials and confer to them inflammatory effects. Most of them are of protein or polysaccharidic nature, as for instance the exotoxins of gram-positive bacteria, and therefore are short-lived in the environment and easily removed from nanomaterials during sterilization procedures. On the other hand, gram-negative endotoxin is a ubiquitous and long-lived contaminant, resistant to sterilization and endowed with high inflammation-inducing capacity. It is known that endotoxin contamination can be responsible for many of the inflammatory effects obtained with micro-particles [45]. Despite this evidence, nanosafety studies have paid only recent and partial attention to the issue of endotoxin contamination of nanoparticles and to the possibility of obtaining misleading results if such contamination is not considered. It is of key importance that guidelines for nanosafety studies include a full characterization of the biologically active contaminants of the nanomaterials under test, to avoid attributing to the material toxic effects that are instead caused by the contaminating endotoxin [112]. Since the endotoxin detection methods in nanomaterials are still challenging, more robust strategies need to be developed and much more attention is required in evaluating the endotoxin contamination in nanomaterials. To identify and avoid biologically active contaminations such as that by LPS, not only the biologists/toxicologists should be aware of the danger and appropriately design and perform their experiments, but chemists should redesign their synthesis processes so as to avoid contamination.

\section{Open access}

This work is licensed under the Attribution-NonCommercialNoDerivatives 4.0 Unported License. To view a copy of this license, visit http://creativecommons.org/licenses/by-nc-nd/4.0/ 
Financial \& competing interests disclosure This study was supported by the EU 7th Framework Programme projects NanoTOES (PITN-GA-2010-264506) (Y Li and D Boraschi), NANoREG (NMP4-LA2013-3105984) (D Boraschi) and QualityNano (INFRA-2010-262163, TA Project: VITOTAF-223) (Y Li), by the Fondazione CARIPLO grant 2011-2114 'Inter-cellular delivery, trafficking and toxicity of engineered nanoparticles in macrophages and CNS cells' (D Boraschi), and by the Italy-Korea GR project 'Nanovaccination: a new strategy for improving antigen-specific immunity' (D Boraschi). The authors have no other relevant affiliations or financial involvement with any organization or entity with a financial interest in or financial conflict with the subject matter or materials discussed in the manuscript apart from those disclosed.

No writing assistance was utilized in the production of this manuscript.

\section{Executive summary}

- Nanoparticles may be contaminated with endotoxin, which can generate misleading results when the toxic and inflammatory effects of nanomaterials are examined, if the presence of endotoxin is overlooked.

Endotoxin contamination in nanomaterials is common

- Endotoxin is a heat-stable ubiquitous contaminant.

- Endotoxin can adhere easily to both negatively and positively charged surfaces.

Biological effects of endotoxin contamination in nanomaterials are significant

- Endotoxin contamination can be responsible of effects such as induction of inflammation, cytotoxicity and apoptosis.

Endotoxin measurement methods can be interfered with by nanoparticles

- Limulus amoebocyte lysate (LAL) assays are the most commonly used endotoxin detection methods.

- LAL assays can be interfered by nanoparticles at the level of readout, enzyme and substrate.

- The validation of LAL assays with nanoparticles should be performed before any endotoxin detection test.

- No LAL format is optimal for all nanoparticle types.

- Bioassays for assessing pyrogens are not specific for endotoxin.

Endotoxin elimination is not easy \& autoclaving is not suitable

- Autoclaving cannot eliminate endotoxin contamination.

- The physico-chemical characteristics of the nanomaterials can be changed after the sterilization/ depyrogenation process.

- Endotoxin removal is difficult, thus preventing contamination during nanoparticle synthesis is the best way for obtaining endotoxin-free particles.

\section{References}

Papers of special note have been highlighted as:

- of interest; $\bullet \bullet$ of considerable interest

1 Yazdi AS, Guarda G, Riteau N et al. Nanoparticles activate the NLR pyrin domain containing 3 (Nlrp3) inflammasome and cause pulmonary inflammation through release of IL- $1 \alpha$ and IL-1B. Proc. Natl Acad. Sci. USA 107(45), 19449-19454 (2010).

2 Hussain S, Boland S, Baeza-Squiban A et al. Oxidative stress and proinflammatory effects of carbon black and titanium dioxide nanoparticles: role of particle surface area and internalized amount. Toxicology 260(1), 142-149 (2009).

3 Gosens I, Post JA, De La Fonteyne L et al. Impact of agglomeration state of nano-and submicron sized gold particles on pulmonary inflammation. Part. Fibre Toxicol. 7(1), 3-7 (2010).

4 Dobrovolskaia MA, Germolec DR, Weaver JL. Evaluation of nanoparticle immunotoxicity. Nat. Nanotech. 4(7), 411-414 (2009).

- General overview on evaluation of nanoparticle immunotoxicity.

5 Zolnik BS, González-Fernández Á, Sadrieh N, Dobrovolskaia MA. Minireview: nanoparticles and the immune system. Endocrinology 151(2), 458-465 (2010).

- Immunostimulation and immunosuppression effects of nanoparticles.
6 Lu YC, Yeh WC, Ohashi PS. LPS/TLR4 signal transduction pathway. Cytokine 42(2), 145-151 (2008).

7 Murphy KM, Travers P, Walport M. Janeway's Immunobiology. Garland Science, NY, USA, 7, (2012).

8 Janeway CA Jr, Medzhitov R. Innate immune recognition. Annu. Rev. Immunol. 20(1), 197-216 (2002).

9 Oostingh GJ, Casals E, Italiani P et al. Problems and challenges in the development and validation of human cell-based assays to determine nanoparticle-induced immunomodulatory effects. Part. Fibre Toxicol. 8(1), 8 (2011).

- Endotoxin contamination among the major issues in assays for immunomodulation by nanoparticles.

10 Liu AH. Endotoxin exposure in allergy and asthma: reconciling a paradox. J. Allergy Clin. Immunol. 109(3), 379-392 (2002).

11 Perros F, Lambrecht BN, Hammad H. TLR4 signalling in pulmonary stromal cells is critical for inflammation and immunity in the airways. Respir. Res. 12(1), 125 (2011).

12 Rylander R. Review: endotoxin in the environment-exposure and effects. J. Endotoxin Res. 8(4), 241-252 (2002).

13 Jacobs RR. Airborne endotoxins: an association with occupational lung disease. Appl. Ind. Hyg. 4(2), 50-56 (1989). 
14 Schwartz DA. Does inhalation of endotoxin cause asthma? Am. J. Respir. Crit. Care Med. 163(2), 305-306 (2001).

15 Michel O, Kips J, Duchateau J et al. Severity of asthma is related to endotoxin in house dust. Am. J. Respir. Crit. Care Med. 154(6), 1641-1646 (1996).

16 Park JH, Gold DR, Spiegelman DL, Burge HA, Milton DK. House dust endotoxin and wheeze in the first year of life. Am. J. Respir. Crit. Care Med. 163(2), 322-328 (2001).

17 Danner RL, Elin R, Hosseini J, Wesley R, Reilly J, Parillo J. Endotoxemia in human septic shock. Chest 99(1), 169-175 (1991).

18 Cani PD, Amar J, Iglesias MA et al. Metabolic endotoxemia initiates obesity and insulin resistance. Diabetes 56(7), 1761-1772 (2007).

19 Malyala P, Singh M. Endotoxin limits in formulations for preclinical research. J. Pharm. Sci. 97(6), 2041-2044 (2008).

20 Gorbet MB, Sefton MV. Endotoxin: the uninvited guest. Biomaterials 26(34), 6811-6817 (2005).

21 Sandle T. A comparative study of different methods for endotoxin destruction. Am. Pharmaceut. Rev. 16(6), 15-17 (2013).

22 Vallhov H, Qin J, Johansson SM et al. The importance of an endotoxin-free environment during the production of nanoparticles used in medical applications. Nano Lett. 6(8), 1682-1686 (2006).

-. Considerations on the importance of endotoxin-free conditions for nanomedicine production.

23 Jones CF, Grainger DW. In vitro assessments of nanomaterial toxicity. Adv. Drug Deliv. Rev. 61(6), 438-456 (2009).

24 Lieder R, Petersen PH, Sigurjónsson OE. Endotoxins-the invisible companion in biomaterials research. Tissue Eng. Part B Rev. 19(5), 391-402 (2013).

25 Darkow R, Groth T, Albrecht W, Lützow K, Paul D. Functionalized nanoparticles for endotoxin binding in aqueous solutions. Biomaterials 20(14), 1277-1283 (1999).

26 Karl DW, Magnusson JC, Carr PW, Flickinger MC. Preliminary assessment of removal of pyrogenic lipopolysaccharides with colloidal zirconia adsorbents. Enzyme Microb. Technol. 13(9), 708-715 (1991).

27 Bromberg L, Chang EP, Alvarez-Lorenzo C, Magarinos B, Concheiro A, Hatton TA. Binding of functionalized paramagnetic nanoparticles to bacterial lipopolysaccharides and DNA. Langmuir 26(11), 8829-8835 (2010).

28 Peula-Garcia J, Molina-Bolivar J, Velasco J, Rojas A, Galisteo-González F. Interaction of bacterial endotoxine (lipopolysaccharide) with latex particles: application to latex agglutination immunoassays. J. Colloid Interface Sci. 245(2), 230-236 (2002)

29 Jiang W, Ghosh S, Song L, Vachet RW, Xing B. Effect of $\mathrm{Al}_{2} \mathrm{O}_{3}$ nanoparticles on bacterial membrane amphiphilic biomolecules. Colloids Surf. B Biointerfaces 102, 292-299 (2013).

30 Li Y, Tran N, Puntes VF, Boraschi D. Bacterial endotoxin binds to the surface of gold nanoparticles and triggers inflammation. Presented at: 7th International
Nanotoxicology Congress Nanotox 2014. Antalya, Turkey, 23-26 April 2014.

31 Martinon F, Pétrilli V, Mayor A, Tardivel A, Tschopp J. Gout-associated uric acid crystals activate the NALP3 inflammasome. Nature 440 (7081), 237-241 (2006).

32 Dostert C, Pétrilli V, Van Bruggen R, Steele C, Mossman BT, Tschopp J. Innate immune activation through $\mathrm{Nalp} 3$ inflammasome sensing of asbestos and silica. Science 320 (5876), 674-677 (2008).

33 Van De Veerdonk FL, Netea MG, Dinarello CA, Joosten LA. Inflammasome activation and IL- $1 \beta$ and IL-18 processing during infection. Trends Immunol. 32(3), 110-116 (2011).

34 Juliana C, Fernandes-Alnemri T, Kang S, Farias A, Qin F, Alnemri ES. Non-transcriptional priming and deubiquitination regulate NLRP3 inflammasome activation. J. Biol. Chem. 287(43), 36617-36622 (2012).

35 Ghonime MG, Shamaa OR, Das $S$ et al. Inflammasome priming by lipopolysaccharide is dependent upon ERK signaling and proteasome function. J. Immunol. 192(8), 3881-3888 (2014).

36 Fernandes-Alnemri T, Kang S, Anderson C, Sagara J, Fitzgerald KA, Alnemri ES. Cutting edge: TLR signaling licenses IRAK1 for rapid activation of the NLRP3 inflammasome. J. Immunol. 191(8), 3995-3999 (2013).

37 Qu G, Liu S, Zhang S et al. Graphene oxide induces toll-like receptor 4 (TLR4)-dependent necrosis in macrophages. ACS Nano 7(7), 5732-5745 (2013).

- TLR4 receptor involved in sensing graphene oxide particles.

38 Chen G-Y, Yang H-J, Lu C-H et al. Simultaneous induction of autophagy and toll-like receptor signaling pathways by graphene oxide. Biomaterials 33(27), 6559-6569 (2012).

39 Bastús NG, Sánchez-Tilló E, Pujals S et al. Peptides conjugated to gold nanoparticles induce macrophage activation. Mol. Immunol. 46(4), 743-748 (2009).

40 Chen Z, Liu Y, Sun B et al. Polyhydroxylated metallofullerenols stimulate IL-1 $\beta$ secretion of macrophage through TLRs/MyD88/NF- $\kappa$ B pathway and NLRP3 inflammasome activation. Small 10(12), 2362-2372 (2014).

41 Hornung V, Bauernfeind F, Halle A et al. Silica crystals and aluminum salts activate the NALP3 inflammasome through phagosomal destabilization. Nat. Immunol. 9(8), 847-856 (2008).

42 Baron L, Gombault A, Fanny M et al. The NLRP3 inflammasome is activated by nanoparticles through ATP, ADP and adenosine. Cell Death Dis. 6(2), e1629 (2015).

43 Cho DR, Shanbhag AS, Hong C-Y, Baran GR, Goldring SR. The role of adsorbed endotoxin in particle-induced stimulation of cytokine release. J. Orthop. Res. 20(4), 704-713 (2002).

44 Ashwood P, Thompson RP, Powell JJ. Fine particles that adsorb lipopolysaccharide via bridging calcium cations may mimic bacterial pathogenicity towards cells. Exp. Biol. Med. 232(1), 107-117 (2007).

45 Brooks R, Wimhurst J, Rushton N. Endotoxin contamination of particles produces misleading inflammatory cytokine responses from macrophages in vitro. J. Bone Joint Surg. Br. 84(2), 295-299 (2002). 
46 Monn C, Becker S. Cytotoxicity and induction of proinflammatory cytokines from human monocytes exposed to fine (PM 2.5) and coarse particles (PM 10-2.5) in outdoor and indoor air. Toxicol. Appl. Pharmacol. 155(3), 245-252 (1999).

47 Chapekar Ms, Zaremba Tg, Kuester Rk, Hitchins Vm. Synergistic induction of tumor necrosis factor alpha by bacterial lipopolysaccharide and lipoteichoic acid in combination with polytetrafluoroethylene particles in a murine macrophage cell line RAW 264.7. J. Biomed. Mater. Res. 31(2), 251-256 (1996).

Inoue K-I, Takano H, Yanagisawa R et al. Effects of airway exposure to nanoparticles on lung inflammation induced by bacterial endotoxin in mice. Environ. Health Perspect. 114(9), 1325 (2006).

49 Shi Y, Yadav S, Wang F, Wang H. Endotoxin promotes adverse effects of amorphous silica nanoparticles on lung epithelial cells in vitro. J. Toxicol. Environ. Health A 73(11), 748-756 (2010).

50 Inoue K-I, Takano H, Yanagisawa R et al. Effects of inhaled nanoparticles on acute lung injury induced by lipopolysaccharide in mice. Toxicology 238(2), 99-110 (2007).

51 Inoue K-I, Takano H, Yanagisawa R, Koike E, Shimada A. Size effects of latex nanomaterials on lung inflammation in mice. Toxicol. Appl. Pharmacol. 234(1), 68-76 (2009).

52 Inoue $\mathrm{K}$, Takano $\mathrm{H}$, Ohnuki $\mathrm{M}$ et al. Size effects of nanomaterials on lung inflammation and coagulatory disturbance. Int. J. Immunopathol. Pharmacol. 21(1), 197-206 (2008).

53 Schwab LP, Xing Z, Hasty KA, Smith RA. Titanium particles and surface-bound LPS activate different pathways in IC-21 macrophages. J. Biomed. Mater. Res. B Appl. Biomater. 79(1), 66-73 (2006).

54 Ma JS, Kim WJ, Kim JJ et al. Gold nanoparticles attenuate LPS-induced NO production through the inhibition of NF$\kappa \mathrm{B}$ and IFN- $\beta /$ STAT1 pathways in RAW264. 7 cells. Nitric Oxide 23(3), 214-219 (2010).

55 Pereira DV, Petronilho F, Pereira HRSB et al. Effects of gold nanoparticles on endotoxin-induced uveitis in rats. Invest. Ophthalmol. Vis. Sci. 53(13), 8036-8041 (2012).

56 Rehman MU, Yoshihisa Y, Miyamoto Y, Shimizu T. The anti-inflammatory effects of platinum nanoparticles on the lipopolysaccharide-induced inflammatory response in RAW 264.7 macrophages. Inflamm. Res. 61(11), 1177-1185 (2012).

57 Dutta D, Sundaram SK, Teeguarden JG et al. Adsorbed proteins influence the biological activity and molecular targeting of nanomaterials. Toxicol. Sci. 100(1), 303-315 (2007).

58 Liu Z, Li W, Wang F et al. Enhancement of lipopolysaccharide-induced nitric oxide and interleukin- 6 production by PEGylated gold nanoparticles in RAW264. 7 cells. Nanoscale 4(22), 7135-7142 (2012).

59 Herzog F, Loza K, Balog S et al. Mimicking exposures to acute and lifetime concentrations of inhaled silver nanoparticles by two different in vitro approaches. Beilstein J. Nanotechnol. 5(1), 1357-1370 (2014).
60 Inoue K-I, Takano H, Koike E et al. Effects of pulmonary exposure to carbon nanotubes on lung and systemic inflammation with coagulatory disturbance induced by lipopolysaccharide in mice. Exp. Biol. Med. 233(12), 1583-1590 (2008).

61 Pulskamp K, Diabaté S, Krug HF. Carbon nanotubes show no sign of acute toxicity but induce intracellular reactive oxygen species in dependence on contaminants. Toxicol. Lett. 168(1), 58-74 (2007).

62 Lucarelli M, Gatti AM, Savarino G et al. Innate defence functions of macrophages can be biased by nano-sized ceramic and metallic particles. Eur. Cytokine Netw. 15(4), 339-346 (2004).

63 US FDA. Guideline on validation of the Limulus Amebocyte Lysate test as an end-product endotoxin test for human and animal parenteral drugs, biological products, and medical devices. U.S. Department of Health and Human Services, Public Health Service, Food and Drug Administration (1987). www.gmpua.com/Validation/Method/LAL

- The first Limulus amoebocyte lysate guidelines for endotoxin detection by the US FDA.

64 USP. Chapter 85: Bacterial endotoxins test. In: United States Pharmacopeia. United States Pharmacopeial Convention, MD, USA (2005).

65 FDA, CBER, CMV, CDRH, ORA. Guidance for industry. Pyrogen and endotoxins testing: questions and answers (2012). www.fda.gov/Drugs/GuidanceCompliance

66 Li Y, Italiani P, Casals E, Tran N, Puntes VF, Boraschi D. Optimising the use of commercial LAL assays for the analysis of endotoxin contamination in metal colloids and metal oxide nanoparticles. Nanotoxicology 9(4), 462-473 (2015).

- Limulus amoebocyte lysate readout can be interfered with by different kinds of nanoparticles.

67 ISO. ISO/FDIS 29701: Nanotechnologies - endotoxin test on nanomaterial samples for in vitro systems - Limulus amebocyte lysate (LAL) test (2010). www.iso.org/iso/iso_catalogue/catalogue_tc/catalogue

- ISO guidelines for endotoxin detection in nanoparticles.

68 Dobrovolskaia MA, Neun BW N, Clogston JD, Ding H, Ljubimova J, McNeil SE. Ambiguities in applying traditional Limulus amebocyte lysate tests to quantify endotoxin in nanoparticle formulations. Nanomedicine 5(4), 555-562 (2010).

69 Dobrovolskaia MA, Neun BW, Clogston JD, Grossman $\mathrm{JH}$, Mcneil SE. Choice of method for endotoxin detection depends on nanoformulation. Nanomedicine 9(12), 1847-1856 (2014).

70 Smulders S, Kaiser JP, Zuin S et al. Contamination of nanoparticles by endotoxin: evaluation of different test methods. Part. Fibre Toxicol. 9(1), 41 (2012).

- Different methods for testing endotoxin in nanoparticles.

71 Kucki M, Cavelius C, Kraegeloh A. Interference of silica nanoparticles with the traditional Limulus amebocyte lysate gel clot assay. Innate Immun. 20 (3), 327-336 (2014). 
72 Twohy CW, Duran AP, Munson TE. Endotoxin contamination of parenteral drugs and radiopharmaceuticals as determined by the limulus amebocyte lysate method. J. Parenter Sci. Technol. 38(5), 190-201 (1984).

73 Spaan S, Heederik DJ, Thorne PS, Wouters IM. Optimization of airborne endotoxin exposure assessment: effects of filter type, transport conditions, extraction solutions, and storage of samples and extracts. Appl. Environ. Microbiol. 73(19), 6134-6143 (2007).

74 Douwes J, Versloot P, Hollander A, Heederik D, Doekes G. Influence of various dust sampling and extraction methods on the measurement of airborne endotoxin. Appl. Environ. Microbiol. 61(5), 1763-1769 (1995).

75 Esch RK, Han L, Foarde KK, Ensor DS. Endotoxin contamination of engineered nanomaterials. Nanotoxicology 4(1), 73-83 (2010).

76 Ragab AA, Van De Motter R, Lavish SA et al. Measurement and removal of adherent endotoxin from titanium particles and implant surfaces. J. Orthop. Res. 17(6), 803-809 (1999).

77 Xu J, Zhang X, Monestier M, Esmon NL, Esmon CT. Extracellular histones are mediators of death through TLR2 and TLR4 in mouse fatal liver injury. J. Immunol. 187(5), 2626-2631 (2011).

78 Mano SS, Kanehira K, Taniguchi A. Comparison of cellular uptake and inflammatory response via toll-like receptor 4 to lipopolysaccharide and titanium dioxide nanoparticles. Int. J. Mol. Sci. 14(7), 13154-13170 (2013).

79 Mano SS, Kanehira K, Sonezaki S, Taniguchi A. Toll-like receptor 4 is involved in titanium dioxide nanoparticle incorporation into cells. Sci. Adv. Mater. 6(7), 1562-1568 (2014).

80 Cui Y, Liu H, Zhou M et al. Signaling pathway of inflammatory responses in the mouse liver caused by $\mathrm{TiO}_{2}$ nanoparticles. J. Biomed. Mater. Res. A 96(1), 221-229 (2011).

81 Özcan I, Bouchemal K, Segura-Sánchez F, Abacı Ö, Özer Ö, Güneri T. Effects of sterilization techniques on the PEGylated poly ( $\gamma$-benzyl-l-glutamate)(PBLG) nanoparticles. Acta Pharm. Sci. 51, 211-218 (2009).

82 Masson V, Maurin F, Fessi H, Devissaguet J. Influence of sterilization processes on poly (e-caprolactone) nanospheres. Biomaterials 18(4), 327-335 (1997).

83 Godara A, Raabe D, Green S. The influence of sterilization processes on the micromechanical properties of carbon fiberreinforced PEEK composites for bone implant applications. Acta Biomater. 3(2), 209-220 (2007).

84 Zheng J, Clogston J, Patri A, Dobrovolskaia M, Mcneil S. Sterilization of silver nanoparticles using standard gamma irradiation procedure affects particle integrity and biocompatibility. J. Nanomed. Nanotechnol. S5, 2 (2011).

85 França Á, Pelaz B, Moros M et al. Sterilization matters: consequences of different sterilization techniques on gold nanoparticles. Small 6(1), 89-95 (2010).

- Sterilization procedures change the characteristic of nanoparticles.

86 Vetten MA, Yah CS, Singh T, Gulumian M. Challenges facing sterilization and depyrogenation of nanoparticles: effects on structural stability and biomedical applications. Nanomed. Nanotech. Biol. Med. 10(7), 1391-1399 (2014).

-• Discussion on the various sterilization and depyrogenation methods for nanoparticles.

87 Petsch D, Anspach FB. Endotoxin removal from protein solutions. J. Biotechnol. 76(2), 97-119 (2000).

88 Magalhães PO, Lopes AM, Mazzola PG, Rangel-Yagui C, Penna T, Pessoa A Jr. Methods of endotoxin removal from biological preparations: a review. J. Pharm. Pharm. Sci. 10(3), 388-404 (2007).

89 Serdakowski London A, Kerins B, Tschantz WR, Mackay K. Endotoxin removal and prevention for pre-clinical biologics production. Biotechnol. J. 7(12), 1509-1516 (2012).

90 Williams KL. Endotoxins: Pyrogens, Lal Testing and Depyrogenation. Informa Healthcare, NY, USA, 167, (2007).

91 Sweadner KJ, Forte M, Nelsen L. Filtration removal of endotoxin (pyrogens) in solution in different states of aggregation. Appl. Environ. Microbiol. 34(4), 382-385 (1977).

92 Sawada Y, Fujii R, Igami I, Kawai A, Kamiki T, Niwa M. Removal of endotoxin from water by microfiltration through a microporous polyethylene hollow-fiber membrane. Appl. Environ. Microbiol. 51(4), 813-820 (1986).

93 Madaeni $S$. The application of membrane technology for water disinfection. Water Res. 33(2), 301-308 (1999).

94 Diogo M, Queiroz J, Prazeres D. Chromatography of plasmid DNA. J. Chromatogr. A 1069(1), 3-22 (2005).

95 London AS, Mackay K, Lihon M, He Y, Alabi BR. Gel filtration chromatography as a method for removing bacterial endotoxin from antibody preparations. Biotechnol. Prog. 30(6), 1497-1501 (2014).

96 Aida Y, Pabst MJ. Removal of endotoxin from protein solutions by phase separation using Triton X-114. J. Immunol. Methods 132(2), 191-195 (1990).

97 Damais C, Jupin C, Parant M, Chedid L. Induction of human interleukin-1 production by polymyxin B. J. Immunol. Methods 101(1), 51-56 (1987).

98 Lerouge S, Wertheimer M, L'H Y. Plasma sterilization: a review of parameters, mechanisms, and limitations. Plasmas Polym. 6(3), 175-188 (2001).

99 Rossi F, Kylian O, Rauscher H, Hasiwa M, Gilliland D. Low pressure plasma discharges for the sterilization and decontamination of surfaces. New J. Phys. 11(11), 115017 (2009).

100 Rossi F, Kylián O, Hasiwa M. Decontamination of surfaces by low pressure plasma discharges. Plasma Process. Polym. 3(6-7), 431-442 (2006).

101 Kylián O, Hasiwa M, Rossi F. Plasma based depyrogenization. Plasma Process. Polym. 3(3), 272-275 (2006).

•• The plasma discharge method for depyrogenation of surfaces.

102 Hasiwa M, Kylián O, Hartung T, Rossi F. Removal of immune-stimulatory components from surfaces by plasma discharges. Innate Immun. 14(2), 89-97 (2008).

103 Kylian O, Hasiwa M, Rossi F. Effect of low-pressure microwave discharges on pyrogen bioactivity. IEEE T Plasma Sci. 34(6), 2606-2610 (2006). 
104 Matthews JB, Besong AA, Green TR et al. Evaluation of the response of primary human peripheral blood mononuclear phagocytes to challenge with in vitro generated clinically relevant UHMWPE particles of known size and dose. J. Biomed. Mater. Res. 52(2), 296-307 (2000).

105 Papageorgiou I, Brown C, Schins R et al. The effect of nanoand micron-sized particles of cobalt-chromium alloy on human fibroblasts in vitro. Biomaterials 28(19), 2946-2958 (2007).

106 Grandjean-Laquerriere A, Laquerriere P, Laurent-Maquin D, Guenounou M, Phillips TM. The effect of the physical characteristics of hydroxyapatite particles on human monocytes IL-18 production in vitro. Biomaterials 25(28), 5921-5927 (2004).

107 Grandjean-Laquerriere A, Laquerriere P, Guenounou M, Laurent-Maquin D, Phillips TM. Importance of the surface area ratio on cytokines production by human monocytes in vitro induced by various hydroxyapatite particles. Biomaterials 26(15), 2361-2369 (2005).
108 Grandjean-Laquerriere A, Tabary O, Jacquot J et al. Involvement of toll-like receptor 4 in the inflammatory reaction induced by hydroxyapatite particles. Biomaterials 28(3), 400-404 (2007).

109 Hitchins V, Merritt K. Decontaminating particles exposed to bacterial endotoxin (LPS). J. Biomed. Mater. Res. 46(3), 434-437 (1999).

110 Herrmann IK, Urner M, Graf S et al. Endotoxin removal by magnetic separation-based blood purification. Adv. Healthc. Mater. 2(6), 829-835 (2013).

111 Lee JJ, Jeong KJ, Hashimoto M et al. Synthetic ligand-coated magnetic nanoparticles for microfluidic bacterial separation from blood. Nano Lett. 14(1), 1-5 (2014).

112 Hankin S, Boraschi D, Duschl A, Lehr C-M, Lichtenbeld $\mathrm{H}$. Towards nanotechnology regulation - publish the unpublishable. Nano Today 6(3), 228-231 (2011).

- The importance of publishing robust nanotoxicity data, including 'no effect' results. 